\title{
Isolation and functional characterization of Lycopene $\beta$-cyclase (CYC-B) promoter from Solanum habrochaites
}

\author{
Monika Dalal1,2, Viswanathan Chinnusamy ${ }^{3}$ and Kailash C Bansal ${ }^{* 1}$
}

\begin{abstract}
Background: Carotenoids are a group of C40 isoprenoid molecules that play diverse biological and ecological roles in plants. Tomato is an important vegetable in human diet and provides the vitamin A precursor $\beta$-carotene. Genes encoding enzymes involved in carotenoid biosynthetic pathway have been cloned. However, regulation of genes involved in carotenoid biosynthetic pathway and accumulation of specific carotenoid in chromoplasts are not well understood. One of the approaches to understand regulation of carotenoid metabolism is to characterize the promoters of genes encoding proteins involved in carotenoid metabolism. Lycopene $\beta$-cyclase is one of the crucial enzymes in carotenoid biosynthesis pathway in plants. Its activity is required for synthesis of both $\alpha$-and $\beta$-carotenes that are further converted into other carotenoids such as lutein, zeaxanthin, etc. This study describes the isolation and characterization of chromoplast-specific Lycopene $\beta$-cyclase (CYC-B) promoter from a green fruited S. habrochaites genotype EC520061.
\end{abstract}

Results: A 908 bp region upstream to the initiation codon of the Lycopene $\beta$-cyclase gene was cloned and identified as full-length promoter. To identify promoter region necessary for regulating developmental expression of the ShCYC-B gene, the full-length promoter and its three different $5^{\prime}$ truncated fragments were cloned upstream to the initiation codon of GUS reporter cDNA in binary vectors. These four plant transformation vectors were separately transformed in to Agrobacterium. Agrobacterium-mediated transient and stable expression systems were used to study the GUS expression driven by the full-length promoter and its 5 ' deletion fragments in tomato. The full-length promoter showed a basal level activity in leaves, and its expression was upregulated $>5$-fold in flowers and fruits in transgenic tomato plants. Deletion of -908 to -577 bp $5^{\prime}$ to ATG decreases the ShCYC-B promoter strength, while deletion of -908 to -437 bp 5 ' to ATG led to significant increase in the activity of GUS in the transgenic plants. Promoter deletion analysis led to the identification of a short promoter region (-436 bp to ATG) that exhibited a higher promoter strength but similar developmental expression pattern as compared with the full-length ShCYC-B promoter.

Conclusion: Functional characterization of the full-length ShCYC-B promoter and its deletion fragments in transient expression system in fruto as well as in stable transgenic tomato revealed that the promoter is developmentally regulated and its expression is upregulated in chromoplast-rich flowers and fruits. Our study identified a short promoter region with functional activity and developmental expression pattern similar to that of the full-length ShCYC$B$ promoter. This 436 bp promoter region can be used in promoter::reporter fusion molecular genetic screens to identify mutants impaired in CYC-B expression, and thus can be a valuable tool in understanding carotenoid metabolism in tomato. Moreover, this short promoter region of ShCYC-B may be useful in genetic engineering of carotenoid content and other agronomic traits in tomato fruits.

* Correspondence: kailashbansal@hotmail.com

1 National Research Centre on Plant Biotechnology, Indian Agricultural Research Institute, New Delhi - 110012, India

Full list of author information is available at the end of the article

\section{Background}

Carotenoids constitute a group of naturally occurring pigments that play diverse roles in plants. Structurally carotenoids are composed of eight isoprene units joined to form a $\mathrm{C} 40$ hydrocarbon skeleton containing conju- 
gated double bonds and linear or cyclic end groups. In chloroplasts, they are part of light-harvesting complexes and also function as antioxidants. Carotenoids accumulate in chromoplasts as secondary metabolites, and impart attractive colors to flowers and fruits. They are important in human diet as they provide $\beta$-carotene, the vitamin A precursor. Owing to their antioxidant activity, they are also commercially used by cosmetic and pharmaceutical industries [1].

Carotenoid biosynthesis has been extensively studied in plants such as tomato, Arabidopsis and pepper [2]. Genes coding for enzymes catalyzing main steps of the carotenoid biosynthesis pathway have been cloned and their expression profiles have also been studied in different species [3-5]. Tomato fruit is a model system for studying the carotenogenesis in plants. Ripening in tomato fruit is associated with vivid changes in color. The change in fruit color from green to orange, pink and then red is accompanied by shift in carotenoid profile from $\beta$-carotene at breaker stage to lycopene at red ripe stage. These changes are brought about by transcriptional upregulation of $P h y$ toene Synthase (PSY1) and Phytoene Desaturase (PDS) genes [6-9] and down regulation of Lycopene $\beta$-cyclase (LCY-B) and Lycopene E-cyclase (CRTL-e) genes [9-12]. Significant increase in carotenoid content was achieved by genetic engineering of carotenoid biosynthesis pathway in canola, rice, potato and maize [13-17]. In contrast to these transgenic crops, only limited success has been achieved in increasing the carotenoid levels in tomato [18-21].

The carotenoid biosynthetic pathway is controlled by a complex regulatory mechanism that includes transcriptional, post transcriptional and feed-back inhibition by end-products [8,22-24]. Moreover, isoprene precursors required for the carotenoid pathway also serve as precursors for phytohormones such as abscisic acid (ABA), gibberellins and secondary metabolites $[25,26]$. Constitutive over-expression of chromoplast-specific PSY1 in tomato has been shown to result in dwarf phenotype, probably by interfering with the gibberellin biosynthesis pathway [27]. Contrary to the expectation, the PSY1 over-expressing transgenic tomato fruit also had reduced lycopene content as compared to untransformed plants [27]. Tomato high-pigment 3 (hp3) mutant showed 30\% increase in carotenoid content in the mature fruit, but exhibited ABA deficiency [28]. Therefore, understanding the regulatory network and metabolic cross-talk between pathways is necessary for metabolic engineering of carotenoids in plants. The success of desired modification in transgenics depends upon the source of transgene; organ to which it is targeted, choice of promoter used, and the key nodes in pathway targeted for modification. The key steps in carotenoid biosynthetic pathway predominantly targeted for transgenic modifications are catalyzed by enzymes such as $P S Y, P D S$ and $L C Y-B$. Although cDNAs of genes encoding carotenoid biosynthetic pathway enzymes have been well characterized in tomato, their promoters have received limited attention. Only PDS promoter has been characterized in tomato [8]. Isolation and characterization of promoters of carotenoid biosynthesis pathway genes will help understand the regulation of carotenoid biosynthesis pathway in tomato.

In this study, we describe the isolation and characterization of $C Y C-B$ (chromoplast-specific lycopene $\beta$ cyclase) promoter from a green fruited Solanum habrochaites genotype EC520061. The CYC-B full-length promoter and its $5^{\prime}$ truncated promoter regions were analyzed by transient and stable expression systems using GUS as reporter gene in tomato. A short promoter region with higher expression level and developmental expression similar to that of full-length promoter was identified.

\section{Results and Discussion}

Tomato genome contains two types of lycopene $\beta$-cyclase genes, $L C Y-B$ and $C Y C-B$, encoding chloroplast- and chromoplast-specific lycopene $\beta$-cyclase enzymes, respectively. $L C Y-B$ is expressed in leaves, flowers and in fruits until breaker-stage of fruit ripening $[10,12]$. The $C Y C-B$ encodes a chromoplast-specific lycopene $\beta$ cyclase and is expressed exclusively in flowers and at breaker-stage of fruit [12]. Lycopene $\beta$-cyclase is one of the crucial enzymes for carotenoid biosynthesis. Lycopene $\beta$-cyclase along with Lycopene $\varepsilon$-cyclase (LYC-E) bring about the cyclization of lycopene. Activities of both of these enzymes together make $\alpha$-carotene, while activity of Lycopene $\beta$-cyclase alone leads to formation of $\beta$ carotene [26]. In pepper also, $L Y C-B$ and CapsanthinCapsorubin Synthase (CCS) genes have been proposed to bring about major changes in carotenoid profiles during ripening in pepper [5]. CCS is a protein with high homology to $C Y C-B$ of tomato, and is highly induced during fruit development $[5,12]$. In watermelon, co-dominant CAPS markers based on a SNP in Lycopene $\beta$-cyclase gene has been developed for allelic selection between canary yellow and red watermelon [29]. Thus, lycopene $\beta$ cyclase plays a major role in carotenogenesis of different colored flowers and fruits. Isolation and characterization of $C Y C-B$ promoter will help understand the regulation of $C Y C-B$ expression in chromoplast-rich organs, and the promoter may be useful in genetic engineering of carotenoid content in plants.

\section{Expression of CYC-B gene in S. lycopersicum and S. habrochaites}

The mRNA levels of $C Y C-B$ gene in leaf and flower, and at different stages of fruit development of S. lycopersicum cv. Pusa Ruby and S. habrochaites genotype EC520061 were determined by semi-quantitative RT-PCR analysis. 
Pusa Ruby fruits show typical color change from green to red during ripening, while $S$. habrochaites (EC520061) fruits remain green even at fully ripe stage. $C Y C-B$ expression was high in the chromoplast-rich tissues such as flowers and fruits, while a low basal level expression was detected in fully developed leaves in both the genotypes (Fig. 1). In Pusa Ruby fruits, $C Y C-B$ expression was highest in breaker stage, and thereafter reduced to a very low level at red-ripe stage. On the contrary, in $S$. habrochaites (EC520061) fruits, CYC-B expression levels were similar in different stages of fruit ripening, and remained high even at fully ripe stage. Expression pattern of $C Y C-B$ in $S$. habrochaites observed in this study was similar to that of $C Y C-B$ gene expression in Beta mutant reported by Ronen et al [12]. Although, Ronen et al [12] could not detect $C Y C$-B expression in wild-type $S$. lycopersicum cv. M82, in this study we could detect expression of CYC-B in leaves, and in fruits at all the stages of ripening in both S. lycopersicum cv. Pusa Ruby and S. habrochaites genotype EC520061. Expression pattern of CYC-B gene, a low level in leaves and high level in chromoplast-rich flowers and fruits, observed in our study is consistent with the expression patterns previously reported for PDS and PSY1 (pTOM5) genes [6,8]. Similarly, CrtR-b2 ( $\beta$-carotene hyroxylase), a chromoplast-specific gene is highly expressed in petals and anthers, and expresses albeit at low level in carpels and sepals, while $C r t R-b 1$, a chloroplast-specific gene shows high level of expression in leaves and sepals but show a low level of expression in flower tissues [24]. Moreover, it was shown that transgenic plants expressing antisense $B($ Beta) did not show any biochemical or developmental alterations in leaves and stems [12]. Thereby implicating that the basal expression level of $C Y C-B$ found in leaves may not have critical role in vegetative tissues.

\section{Isolation of CYC-B promoter}

The promoter region of $C Y C-B$ gene from $S$. habrochaites genotype EC520061 and S. lycopersicum genotype EC521086 was isolated by directional genome walking PCR using a set of walker primers and gene-specific primers. Comparison of the sequence of the DNA fragment cloned from $S$. habrochaites with the coding sequence of $C Y C-B$ coding sequence [GenBank: AF254793] revealed the presence of 908 bp fragment upstream to the start codon of $C Y C-B$ gene. The $908 \mathrm{bp}$ fragment upstream to the ATG codon was designated as ShCYC-B full-length promoter (Fig. 2). The nucleotide sequence of $S h C Y C-B$ promoter cloned in this study was deposited at NCBI [GenBank: DQ858292]. The DNA
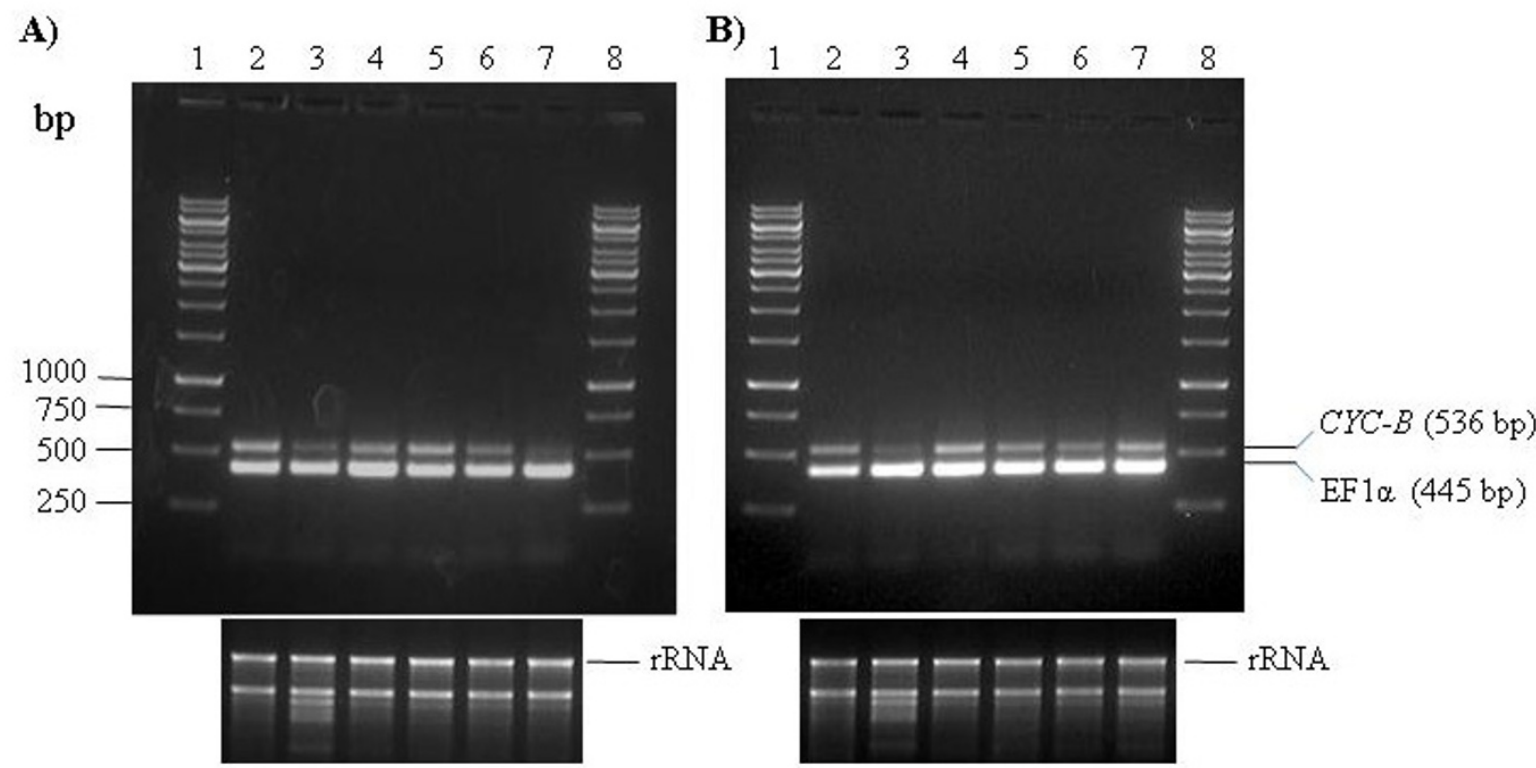

Figure 1 Expression levels of lycopene $\beta$-cyclase (CYC-B) in different tissues of S. lycopersicum and S. habrochaites. RT-PCR was performed with total RNA isolated from leaves, flowers and fruits at different stages of development. (A) Wild-type tomato cv. Pusa Ruby (S. lycopersicum); Lanes 2-3, flower and leaf, respectively; Lanes 4-7; fruit at different stages of ripening, from mature green (lane 4), breaker (Lane 5), orange (lane 6) to red ripe stage (Lane 7). (B) S. habrochaites genotype EC520061. Lanes 2-3, flower and leaf, respectively; Lanes 4-7, fruit with progressive stages of ripening, from mature green (Lane 4) to ripe stage (Lane 7). In case of S. habrochaites, which is a green fruited genotype, progress of ripening was broadly defined on the basis of seed color and development (see Materials and Methods). Lanes 1 and 8, 1 kb Mol. weight marker. 
ShCYC-B GACTTCACCCTTCTTTCTTGTCTTGGTGCCCGTTTTÄTGGTCTGMCHACGGCGTGATGC 60 SICYC-B ACGATG 8

ShCYC-B CAAATTCTGCCGCTCCACAGTGMGCATTTCGATCTACTGGAMATTGACCAMCTTATTTTA 120 SICYC-B CAAATTCTGCCGCTCCACAGTGMGCATTTCGATCTACTGGAMATGMCCAACTTATTTTA 68 3

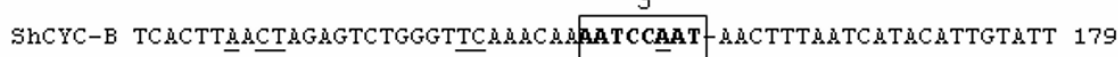
SICYC-B TCACTTGATAA--------CTAMACAMATCCTATHAACTTTAMTCATACATTGTATT 118 4 ShCYC-B TATATTGAAAAA ATTATGCACAACTCAGTAMATTACCTTTTTTAGCAGTCAMAAATTCTA 239 SICYC-B TATACCGAAAAMGTATGCATAMCTCAGTAMATTACCTTTTTTAGCAGTCAMA--TTCTA 176

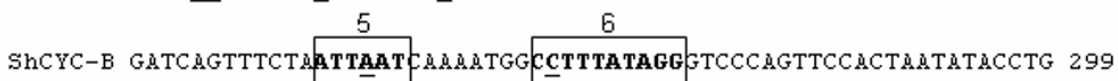

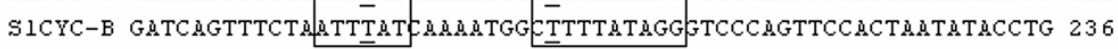
ShCYC-B CCG ACCATGCACTGMCTACAMGMCAAAT ACCTCACTÄTGTTTGTTMGTGCTTGGTÄTÄT 359 SICYC-B CCGICCATGCACTGACTACAMGACAAATACCTCACTATGTTTGTTAGTGCTTGGTAMTAT 296

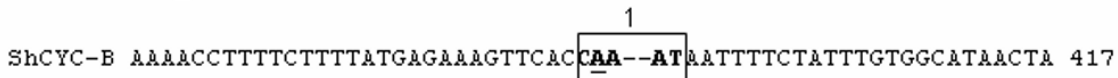
SICYC-B AMACCTTTTCTTTTATGAGAMGTTCACEGAGAMTATTTTCTATTTGTGGCATAMCTA 356 ShCYC-B GTATCGAMGTATATAGTGCAGATTGACAMGAMTTAMTTTTGCAGTTGGGCACATGAMCA 477 SICYC-B -------GTATATAGTGCAGATTGACAMGAMTTTAMTTTTGCAGTTGGGCACATGAMCA 408 7 8 ShCYC-B ATTTTCCTCAMAGTTGTAGAMALTATTTTTCATTTTCTTGTCACCGAMAMTTATTTATÄ 537 SICYC-B ATTTTCCTCAMATTGTAGAMGTACTTTCATTTTCTTGTCACCGMAMTTATTTATA 468 ShCYC-B TTGAMATTGAMACCGAMTGAGCTGCAMGACTCGAGTCGMATTTCAAA AמAATTGACCAAC 597 SICYC-B TTGAMATT

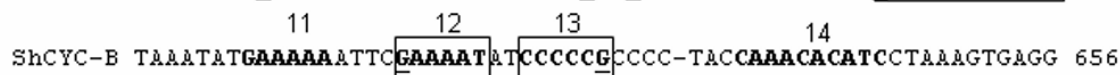

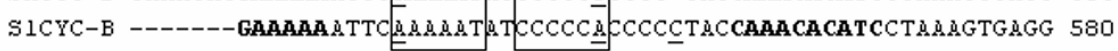

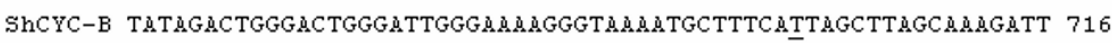
SICYC-B TATAGACTGGGACTGGGATTGGGAMAMGGTAMAMTGCTTTCACTAGCTTAGCAMAGATT 640 15 ShCYC-B CCACTTTGTTÄGCTàTCTTTCTTTCTCATTTCCTĆTTTTCTTTTTCTTTTTTT-GTTäTä 775 SICYC-B CCACTTTGTTAGCTATCTTTCTTTCTCATTTCCTTTTTTCTTTTTCTTTTTTTIGTTATA 700 14 ShCYC-B TAAGCCAMAGTAGGTACCCAAAAGCATCAATATTTTGTATTGCTTGGTGATTCCTCTTTA 835 SICYC-B TAMGCCAMAGTAGGTACCCAAAAGCATCAMTATTTTGTÄTTGCTTGGTGATTCCTCTGTÄ 760 15 ShCYC-B GTCCAGTATTTCATTTTCTACÄGTTCCGCCTCCCTCCATAMTTÄACCATTATCÄTCTT 895 SICYC-B GTCCAGTATTTCATTTTCTACAAGTTCCACCTCCCTCCATAATTACCATTATCAATCTT 820 ShCYC-B -TACATTTTCTATA 908 SICYC-B ATACATTCTCTATA 834

Figure 2 Sequence comparison and putative cis--elements identified in the CYC-B promoter from S. habrochaites and S. lycopersicum. The cis-elements are numbered 1-15, cis-elements shared by the promoters are shown in bold; elements that are exclusive in one of the promoters are shown in boxes, difference in nucleotide is underlined. 1) CAAT Box; 2) RAP2.2; 3) rbcS consensus sequence; 4) GT1 CONSENSUS; 5) conserved DNA module for light responsiveness; 6) CARGAT CONSENSUS; 7) ROOT MOTIF TAPOX1;8) TATA box; 9) ERE LEE4; 10) L-box of S. lycopersicum, part of a light responsive element; 11) GT1 GM SCAM4; 12) GT1CONSENSUS; 13) GC-motif; 14) CIACADIANLELHC; 15) INRNTPSADB; The 5' upstream sequence of CYC-B gene is submitted at NCBI [ShCYC-B and SICYC-B promoter GenBank accession numbers are DO858292 and EU825694, respectively]. The ciselements are described in detail in Table 1. 
fragment cloned from S. lycopersicum contained 834 bp promoter region [GenBank: EU825694]. The ShCYC-B promoter sequence was analyzed for transcription start site (TSS) and potential cis-acting transcription factor binding sites. Neural Network Promoter Prediction [30] identified a TSS at 303 bp 5 to ATG. PLACE [31] and PlantCARE [32] analysis revealed a potential TATA box at $381 \mathrm{bp} 5$ to ATG and $72 \mathrm{bp}$ upstream to the potential TSS. Several CAAT boxes, a RAP2.2 transcription factor binding site, an ethylene responsive element $(E R E)$, circadian elements and light responsive elements were found in the ShCYC-B promoter (Fig. 2). A list of some of the relevant cis-elements detected and their relative positions from the translational start site ATG is given in Table 1. A comparison of the $C Y C-B$ promoters from $S$. lycopersicum and S. habrochaites revealed that ERE (ATTTCAAA) cis-element was conserved between these two promoters (Fig. 2). This ERE cis-element was also reported in $C Y C-B$ promoter of Beta gene [12]. This indicates ethylene responsive regulation of $C Y C-B$ promoter during fruit ripening. The RAP2.2 transcription factor binding site ATCTA [33] was also found in both the $C Y C-B$ promoters cloned in this study. The cis-element ATCTA has been found to be conserved in promoters of genes involved in carotenoid and tocopherol biosynthesis, and certain photosynthesis-related genes in Arabidopsis [33,34]. However, there were many elements that were exclusively present in $S h C Y C-B$ promoter but not in $S l C Y C-B$ promoter. These include $r b c S$ general consensus sequence, CArG consensus sequence found in the promoter of flowering-time gene (AtSOC1), L-Box (a part of light responsive element) and GT-1 element, which are known to play important role in gene expression (Table 1).

\section{Transient and stable expression of ShCYC-B promoter in tomato}

To characterize the putative $S h C Y C-B$ promoter, promoter:: $\beta$-glucuronidase (GUS) reporter gene fusion constructs were prepared for full-length and its 5 ' deletion fragments, and transformed into Agrobacterium (Fig. 3). Binary vector pBI121 having constitutive CaMV35S promoter::GUS reporter gene was used as control. Functional analysis was carried out by transient in fruto expression in tomato fruits, and stable expression in transgenic tomato. In transient expression analysis, GUS activity was evident in columella and placental tissues in both green stage and ripe stage of tomato fruit (Fig. 4). This qualitative GUS assay revealed that the full-length ShCYC-B promoter as well as its deletion fragments were able to drive the expression of reporter gene in different developmental stages of tomato fruit.

To identify putative cis-elements required for developmental and tissue-specific expression of $S h C Y C-B$ promoter, tomato transgenic plants were generated. Six to nine independent transgenic lines for each construct were screened in $\mathrm{T}_{0}$ generation on the basis of PCR and histochemical GUS staining. There was no difference in the localization of GUS activity in fruits among fulllength and truncated promoter constructs at various stages of fruit development. GUS staining was visible in vascular bundles, columella, placental tissue and seeds. In case of D0-908 (full-length $C Y C-B$ promoter) and D3-436 (the shortest promoter fragment) lines, locular tissue was also highly stained. However, there was no GUS activity in epidermis. The intensity of GUS staining was relatively similar among independent events for each construct, though one or two events of D1-818 and D2-578 transgenics showed variation in the intensity of GUS stain. Among the 9 independent events examined for D2- 567 transgenic plants, 7 plants showed consistently lower GUS intensity as compared to that of full-length and other deletion constructs (data not shown). About 4-5 individual events for each construct were carried forward to $\mathrm{T}_{1}$ for further analyses.

$\mathrm{T}_{1}$ seeds were selected on kanamycin and screened by PCR. For each construct, 2-3 events were subjected to Southern analysis to determine transgene copy number (Additional file 1, Fig. S1). Subsequently, plants having single copy insertions were analyzed for promoter activity by northern analysis, and histochemical as well as quantitative GUS assays. Since there was no visible difference in GUS staining of D0-908 and D1-818 transgenic fruits, and no single copy $\mathrm{T}_{1}$ plants were available in D1-818, plants harboring this construct were not included in further analysis. To examine the tissue-specific expression, leaf, root, flower and fruits at different developmental stages from single copy transgenic plants for each construct were subjected to histochemical GUS staining. GUS activity was apparently not detectable by visual observations in transgenic roots (Fig. 5A) and leaves (Fig. $5 B)$ transformed with the $S h C Y C-B$ full-length or truncated promoter constructs. The transgenic flowers harboring either full-length $\operatorname{ShCYC-B}$ promoter or its $5^{\prime}$ deletion fragments showed GUS staining mainly in stamens, while there was little or no GUS staining in petals (Fig. 5C-D). Similar kind of GUS staining was observed in the flowers of transgenic tomato expressing PDS promoter-driven GUS reporter gene [8]. The CaMV35S::GUS transgenic plants showed GUS staining both in leaves and flowers (Fig. 5). In $\mathrm{T}_{1}$ fruits, localization of GUS activity was similar to that observed in $\mathrm{T}_{0}$ fruits for all ShCYC-B promoter constructs. In fruits, D2578 consistently showed lower GUS intensity, while the GUS staining was highest in D3-436 (the shortest promoter fragment). The activity of full-length and truncated promoter driven GUS was low at green fruit stage, and showed an upregulation at breaker and orange stages 
Table 1: List of cis-elements identified in 908 bp ShCYC-B promoter sequence

\begin{tabular}{|c|c|c|c|}
\hline Name of Cis-element & Sequence & Position from ATG & Description \\
\hline RAP2.2 & ATCTA & -817 & $\begin{array}{l}\text { RAP2. } 2 \text { cis-element is } \\
\text { conserved in promoters of } \\
\text { genes involved in carotenoid } \\
\text { and tocopherol biosynthesis, } \\
\text { and certain photosynthesis- } \\
\text { related genes in Arabidopsis. } \\
\text { It confers strong basal activity } \\
\text { to promoter }\end{array}$ \\
\hline rbcS consensus sequence & AATCCAA or AATCCAAC & -759 & $\begin{array}{l}\text { Influences the level of gene } \\
\text { expression and involved in } \\
\text { light regulated gene } \\
\text { expression }\end{array}$ \\
\hline GT1 consensus & GAAAAA & $\begin{array}{l}-224,-230,-294,-304,-386,- \\
413,-557,-723,-809\end{array}$ & $\begin{array}{l}\text { Consensus binding site in } \\
\text { many light-regulated genes, } \\
\text { GT-1 can stabilize the TFIIA- } \\
\text { TBP- TATA box complex }\end{array}$ \\
\hline GT1 GM SCAM4 & GAAAAA & $-304,-723$ & $\begin{array}{l}\text { GT-1 motif found in the } \\
\text { promoter of soybean, } \\
\text { Interacts with a GT-1-like } \\
\text { transcription factor }\end{array}$ \\
\hline CArGAT consensus & cCWWWWWWGG & -643 & $\begin{array}{l}\text { Cis-element found in the } \\
\text { promoter of } A t S O C 1 \text {, a MADS- } \\
\text { box flowering-time gene. } \\
\text { Flowering Locus } C \text { (FLC) } \\
\text { protein binds to GArG box in } \\
\text { SOC1 promoter and represses } \\
\text { the expression of } S O C 1 \text {. }\end{array}$ \\
\hline ROOT MOTIF TAPOX1 & ATATT & $-104,-409,-728$ & $\begin{array}{l}\text { Motif found in promoters of } \\
\text { rolD and root-specific genes }\end{array}$ \\
\hline ERE & AWTTCAAA & -332 & $\begin{array}{l}\text { Ethylene responsive element } \\
\text { found in tomato E4 promoter } \\
\text { and other senescence } \\
\text { associated gene promoters. It } \\
\text { is required for ethylene- } \\
\text { mediated expression. }\end{array}$ \\
\hline L-box & AАATTAACCAAC & -323 & $\begin{array}{l}\text { Part of a light-responsive } \\
\text { element }\end{array}$ \\
\hline CIACADIANLELHC & CAANNNNATC & $-115,-273$ & $\begin{array}{l}\text { Region necessary for circadian } \\
\text { expression of tomato Lhc } \\
\text { gene }\end{array}$ \\
\hline INRNTPSADB & YTCANTYY & $-64,-168,-403$ & $\begin{array}{l}\text { Inr (initiator) elements found } \\
\text { in tobacco psaDb promoter } \\
\text { without TATA boxes, element } \\
\text { responsible for light } \\
\text { responsive transcription }\end{array}$ \\
\hline
\end{tabular}

of fruit development (Fig. 6). Since ERE (ATTTCAAA) cis-element was found at -332 bp 5 to ATG of $S h C Y C-B$ promoter, we examined whether ethylene could induce the expression of $C Y C-B$ promoter in vegetative tissues. Foliar spray of Ethephon (1-5\%) did not induce $C Y C-B$ promoter in the seedlings of full-length and deletion transgenic lines (data not shown). This suggests that developmental (flower and fruit) cues are required to induce CYC-B promoter.

\section{Quantitative GUS assay}

The visual observations made by histochemical GUS staining in leaf, flower and different developmental stages of fruit, were quantified by fluorometric MUG (4-methylumbelliferone glucuronide) assay. Tomato transgenic 

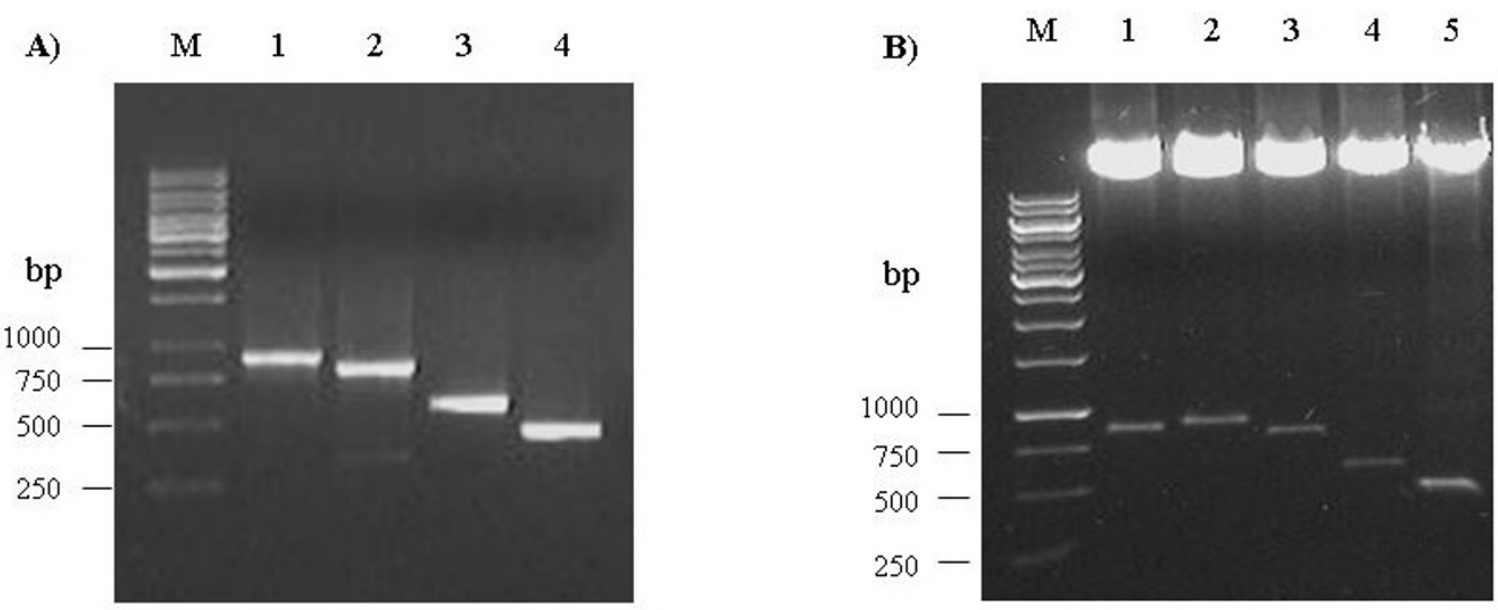

C)

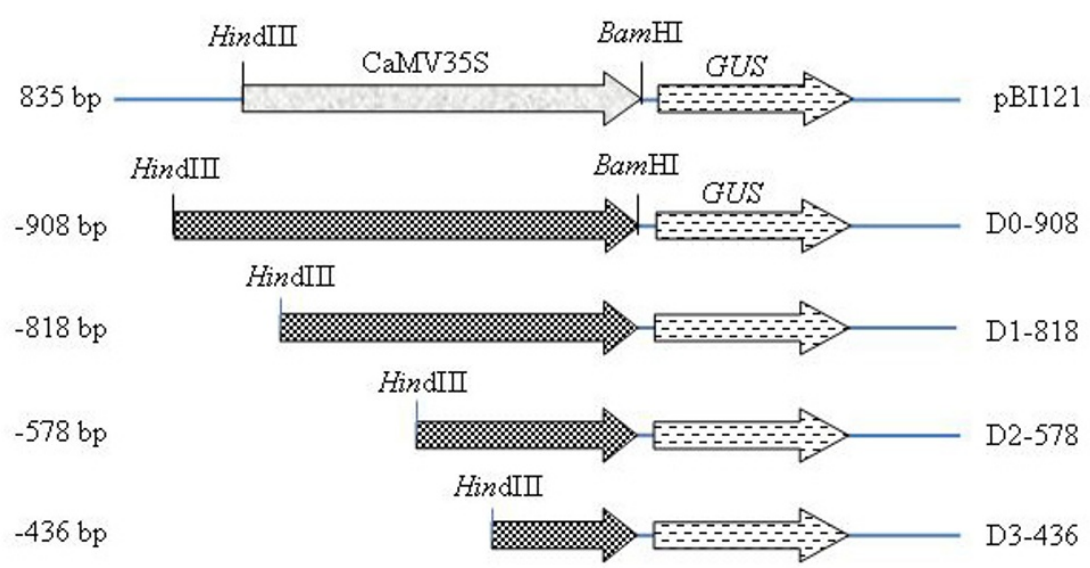

Figure 3 Cloning of ShCYC-B full-length promoter and its deletion fragments in binary vector. (A) PCR amplification of full-length and $5^{\prime}$ deletion fragments of ShCYC-B promoter. M, 1 kb Mol. wt. marker; Lanes 1-4, amplicons of 908 bp, 818 bp, 578 bp and 436 bp, respectively. (B) Restriction confirmation of cloning of full-length and deletion fragments of ShCYC-B promoter in binary vectors. M, 1 kb Mol. wt. marker; Lanes 1-5, plasmids pB1121, pD0-908, pD1-818, pD2-578 and pD3-436, respectively, restricted with Hindlll and BamHI. (C) Schematic illustrations of ShCYC-B promoter and its deletion fragments. The numbers on the left indicate the 5 ' end points of the promoter fragments relative to the translational start site. Binary vector pBI121 having GUS gene driven by CaMV35S promoter was used as a positive control.

plants harboring pBI121 (constitutive CaMV35S promoter-driven GUS) were also included in the analysis. CaMV35S promoter driven GUS activity was lowest in flowers, and increased about 4- and > 8-fold in leaves and fruits, respectively (Fig. 7A). The expression pattern of full-length $S h C Y C$-B promoter as determined by GUS activity (Fig. 7B) was similar to that of the expression pattern observed by RT-PCR analysis in S. habrochaites (Fig. 1B). In full-length $S h C Y C-B$ promoter transgenic plants, GUS activity was about 5- and > 12-fold higher in flower and fruits, respectively, as compared with leaves. Similarly, ShCYC-B D2-578 and D3-436 promoter transgenic plants also showed lower GUS activity in leaves as compared to flower and fruits (Fig. 7B). It appears that ShCYC-B promoter activity in leaves is too low to be detected by histochemical GUS staining. The D2-527 promoter transgenic plants consistently showed lowest GUS activity as compared to full-length and D3-436 truncated-promoter transgenic plants in all the tissues. Although the promoter strength of D3-436 was similar to that of full-length promoter in green fruits, D3-436 promoter showed higher activity than full-length promoter in leaves, flowers, and breaker-, orange- and red-stages of fruits (Fig. 7B). Most noticeably, the shortest promoter fragment D3-436 showed 4.5 and 5.11-fold higher GUS activity in flowers and leaves, respectively, as compared to that of D0-908 full-length promoter (Fig. 7B).

\section{Northern-blot analysis}

Northern blot was performed to analyze the relative levels of $C Y C-B$ full-length or truncated promoter driven GUS expression in different tissues namely leaf, flower 


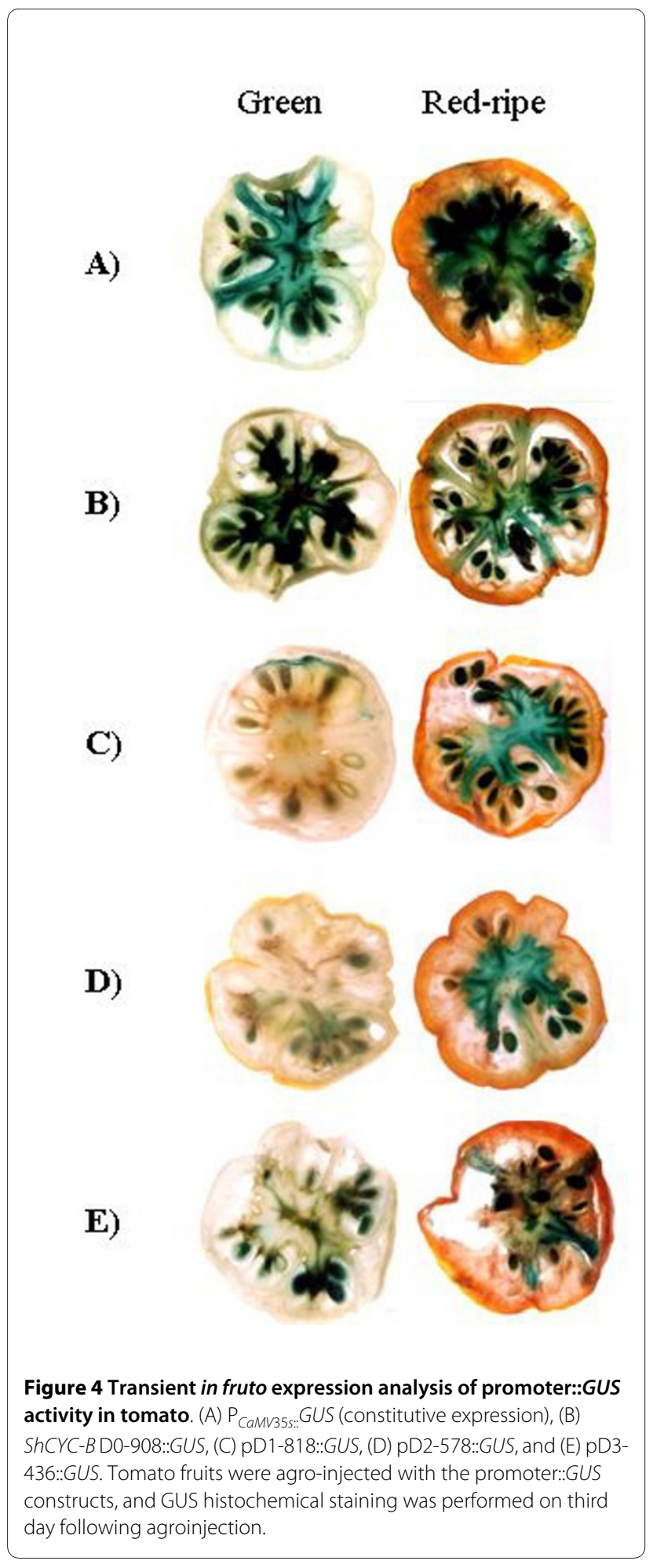

and fruits from transgenic tomato plants. Blots used for detecting GUS mRNA levels were reprobed with $E F 1 \alpha$ that served as a loading control for amount of total RNA. The concentration of total RNA loaded per lane for a particular stage of development or tissue was essentially same for transgenic lines of each construct, but was varying in the range of 20-30 $\mu \mathrm{g}$ across different stages or tissues used. ShCYC-B full-length promoter and its deletion fragments showed low expression in chloroplast-rich green leaves and green fruits, while their expression was high in chromoplast-rich flowers, and fruits at breaker and orange stage of ripening (Fig. 8). Consistent with GUS assay, in northern analysis also, D3-436 promoter fragment showed highest promoter activity in flowers (Fig. 8). However, in contrast to the higher GUS-activity observed in fruits of transgenic plants expressing D3-436 promoter driven GUS reporter, the transcript levels of D3-436 promoter driven GUS were not so apparently higher than that of D0-908 promoter driven GUS reporter. The deletion fragment D2-578 showed lowest promoter strength as compared to the full-length promoter and D3-436. The reduction in GUS expression in D2-578 transgenic plant does not appear to be due to transgene position and/or silencing effect, as seven out of nine independent events showed reduced GUS staining, and the transgenic plants with single insertion for D2-578 fragment were selected for analysis.

The present study clearly showed that the $S h C Y C-B$ promoter is developmentally regulated and its expression is upregulated in chromoplast-rich flowers and fruits at different stages of ripening. The promoter strength was drastically decreased by a deletion of -908 to $-568 \mathrm{bp} 5^{\prime}$ to ATG as compared to full-length promoter, while the shortest D3-436 promoter fragment showed highest activity. This suggests that nucleotide sequence -567 to 437 bp upstream to initiation codon may contain cis-elements involved in down regulation of $C Y C-B$ expression, while nucleotide sequences -908 to -568 bp upstream to initiation codon might be involved in negating the repressive nature of regulatory sequences in -567 to -434 bp $5^{\prime}$ to ATG. The RAP2.2 binding cis-element ATCTA has been shown to confer strong basal activity in $P S Y$ promoter from Arabidopsis [33]. This cis-element was found in $S h C Y C-B$ full-length promoter at -817 to $-813 \mathrm{bp}$ upstream to ATG, and might contribute to the basal activity of full-length promoter, as deletion of this cis-element in D2-578 resulted in considerable decrease in promoter activity. The presence of three GT-1 cis-element (GAAAAA), one at -723 to -718 and two at -304 to -299 and -294 to -289 bp upstream of ATG might be playing a role in the gene expression. GT-1 element was initially identified as cis-element regulating cell-type specific expression specifically in light regulated genes. GT-1 protein binds to TFIIA and TATA-binding proteins. The GT1 cis-element is conserved in many plant promoters, and may have positive or negative regulatory effect on transcription depending upon cell type $[35,36]$. 


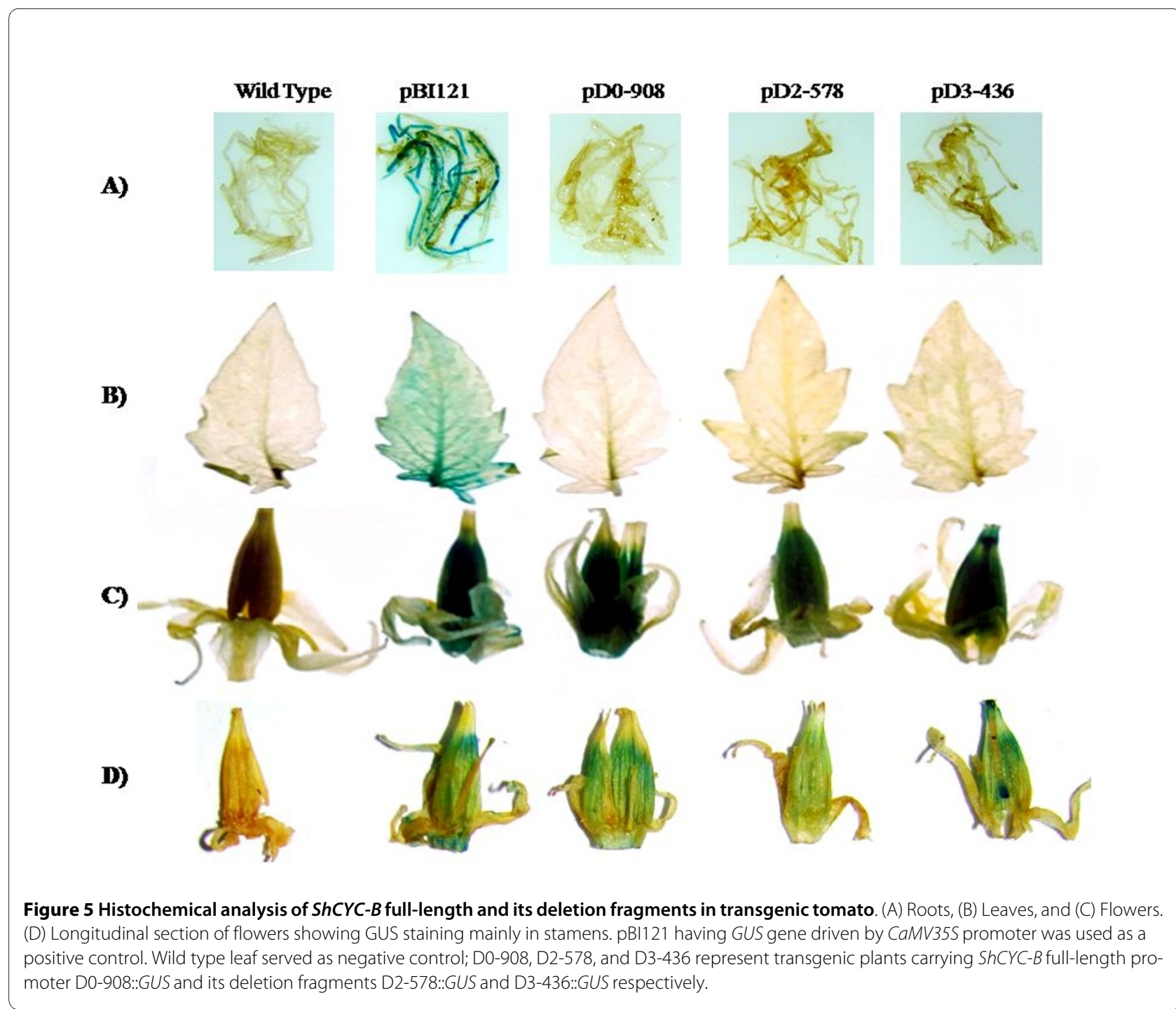

\section{Conclusion}

In this study, Lycopene $\beta$-cyclase $(C Y C$ - $B$ ) promoter from Solanum habrochaites, a green fruited tomato genotype, was isolated and functionally characterized in transient in fruto and stable transformation systems. Conservation of cis-elements such as RAP2.2 binding cis-element and $E R E$ cis-element between $C Y C-B$ and $P S Y$ promoter suggests a common regulatory mechanism for carotenoid accumulation in fruits. A short promoter region with promoter activity and developmental expression pattern comparable to that of full-length $S h C Y C-B$ promoter was identified. As signal transduction events and transcription factors that developmentally regulate the $C Y C-B$ expression are not known, the short promoter region identified in this study can be used in promoter::reporter fusion molecular genetic screens to identify mutants impaired in $C Y C-B$ expression, and thus can be a valuable tool in understanding carotenoid metabolism in tomato.

\section{Methods}

Isolation and cloning of ShCYC-B promoter

Isolation of 5 ' flanking region of $C Y C-B$ gene from $S$. lycopersicum genotype EC521086 and S. habrochaites genotype EC520061 was carried out following PCR-based directional genome walking method [37]. Genomic DNA was extracted from leaves following cetyl trimethyl ammonium bromide (CTAB) method [38]. In the primary PCR, genomic DNA was used as template. Amplification was carried out with biotinylated gene specific reverse primer (R1) along with one of the four universal walker primers namely Walker 1, Walker 2, Walker 3 and Walker 4 (Table 2) in four different reactions. The PCR conditions were as follows: initial denaturation at $94^{\circ} \mathrm{C}$ for $4 \mathrm{~min}$ followed by 33 cycles of $94^{\circ} \mathrm{C}(1 \mathrm{~min}), 47^{\circ} \mathrm{C}(1$ $\min )$, and $72^{\circ} \mathrm{C}(2 \mathrm{~min})$, and then final extension at $72^{\circ} \mathrm{C}$ for $7 \mathrm{~min}$. The purified and diluted primary PCR product was used as template for nested PCR with one nested 


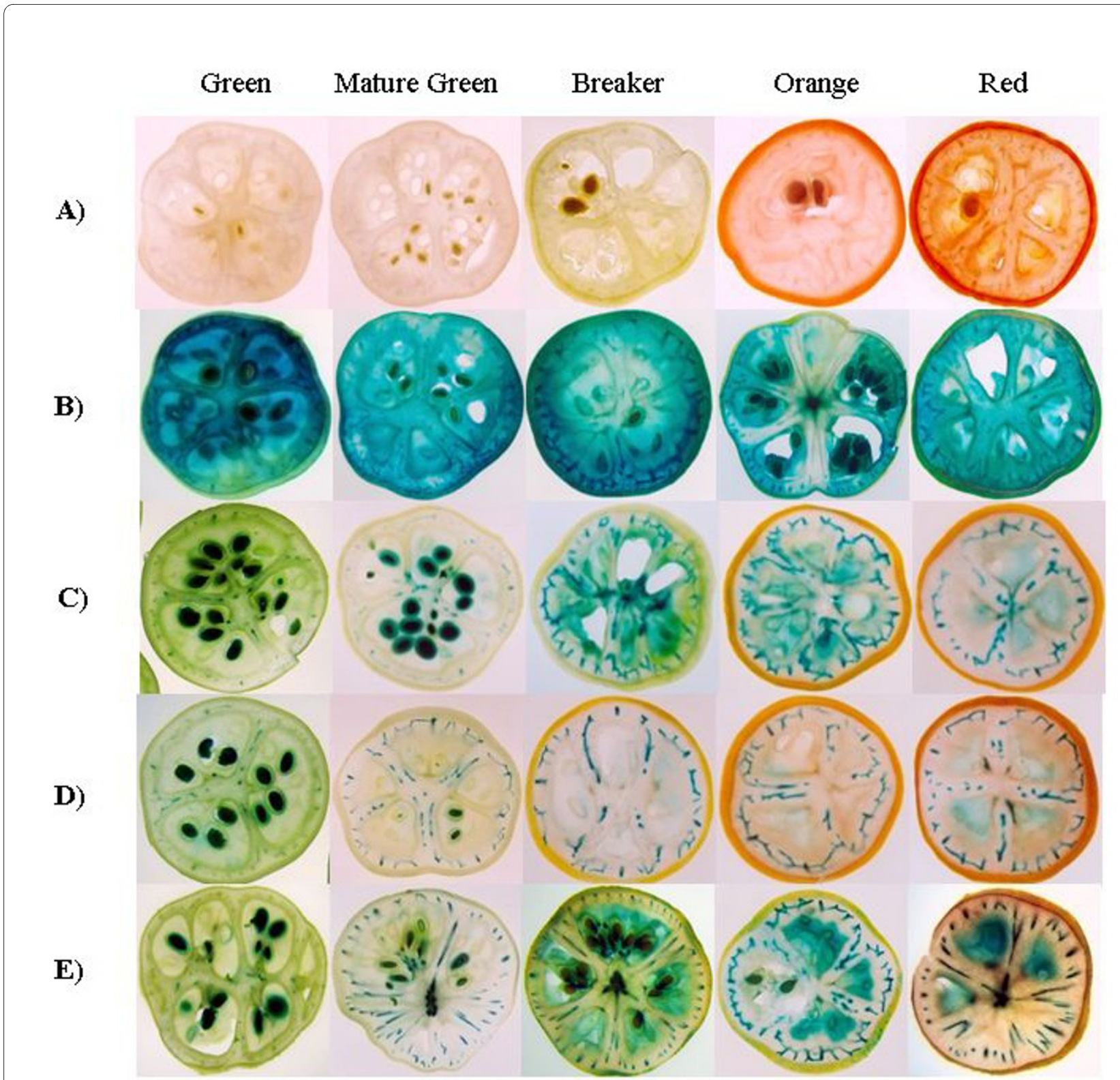

Figure 6 Histochemical analysis of ShCYC-B full-length and its deletion fragments in tomato fruits. GUS expression in (A) wild-type fruits, (B) transgenic fruits carrying $P_{\text {Camv355: }}$ GUS (constitutive promoter), and (C-D) transgenic fruits carrying ShCYC-B full-length promoter D0-908::GUS and its deletion fragments D2-578::GUS and D3-436::GUS, respectively in early green, mature green, breaker, orange and red ripe stages of fruit ripening. The images of different stages of fruits were derived from one representative line harboring single copy of transgene for each ShCYC-B promoter construct.

gene specific reverse primer (R2) and adaptor walker primer (Table 2). The gene specific primers (R1 and R2) were designed on the basis of chromoplast-specific lycopene $\beta$ cyclase $(C Y C-B)$ cDNA sequence [GenBank: AF254793] [12]. The secondary PCR product was gel purified, cloned in pDrive vector (QIAGEN) and sequenced.

\section{Analysis of the ShCYC-B Promoter Sequences}

The 5 ' flanking sequence upstream to ATG of the $C Y C-B$ cDNA was searched for known transcription factor binding sites using the PLACE [31] and PlantCARE [32] databases. Transcription start site was predicted by using Neural Network Promoter Prediction softwares [ [30]; http://www.fruitfly.org/seq_tools/promoter.html]. 

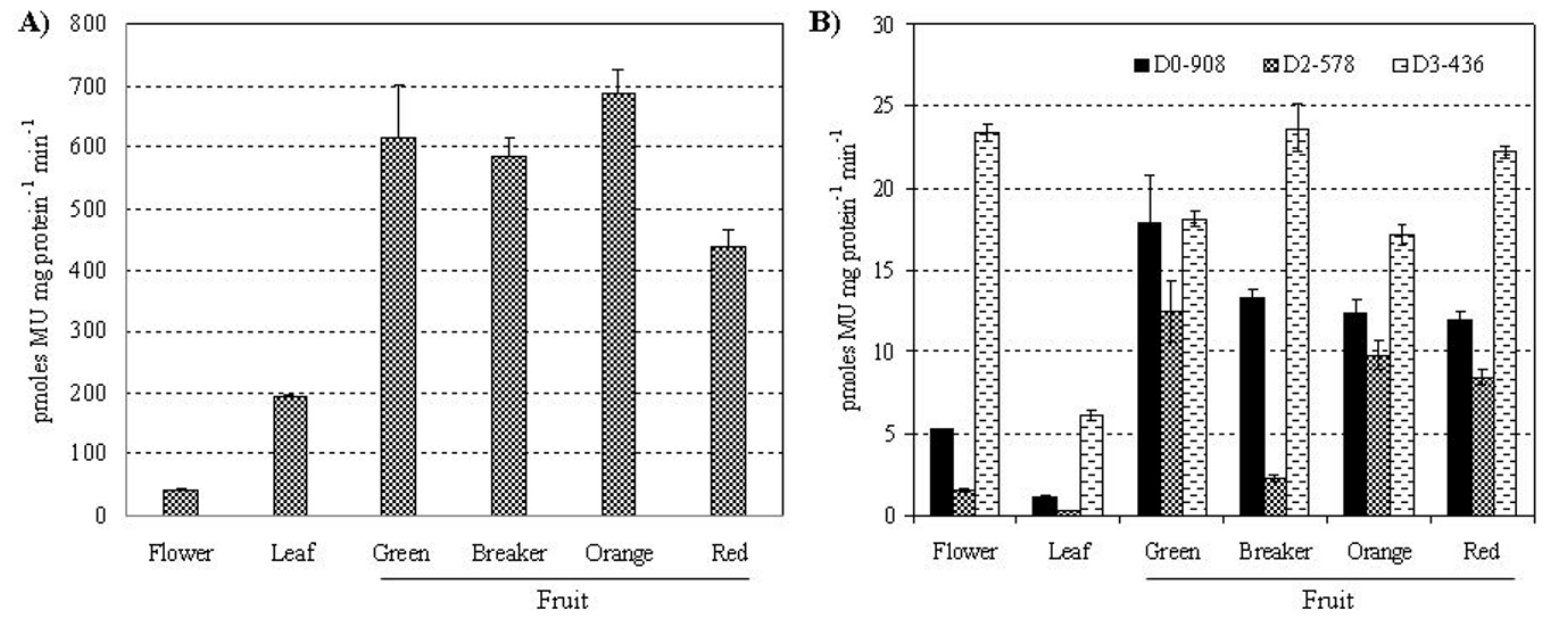

Figure 7 Fluorometric quantification of GUS activity in transgenic tomato plants. (A) Tissues from transgenic plants harboring $P_{\text {Camv35s: }}$ GUS (constitutive promoter), (B) ShCYC-B full-length promoter D0-908::GUS and its deletion fragments D2-578::GUS and D3-436::GUS, respectively. Samples from 2-3 lines from single copy transgenic events (two events per construct) were pooled and used for quantitative MUG assay. Plant tissues were homogenized in protein extraction buffer. The supernatant was used for protein quantification and fluorometric assay. Reading at zero time point served as a control. The amount of 4-MU was determined from a standard curve. GUS activity was expressed as pmol 4-MU mg protein ${ }^{-1} \mathrm{~min}^{-1}$. Data are presented as the mean ( \pm standard error) of GUS activity from three independent determinations.

A)

\begin{tabular}{|c|c|c|c|c|c|c|c|c|c|c|c|c|c|c|c|c|c|}
\hline \multicolumn{3}{|c|}{ Flower } & \multicolumn{3}{|c|}{ Leaf } & \multicolumn{3}{|c|}{ Green } & \multicolumn{3}{|c|}{ Breaker } & \multicolumn{3}{|c|}{ Orange } & \multicolumn{3}{|c|}{ Red } \\
\hline $\begin{array}{l}\infty \\
\text { ᄋ } \\
\text { ㅇ } \\
\text { مे }\end{array}$ & $\begin{array}{l}\infty \\
\infty \\
\omega \\
\tilde{\sigma} \\
\tilde{\sigma}\end{array}$ & 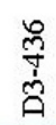 & $\begin{array}{l}\infty \\
\stackrel{\circ}{\circ} \\
\grave{\delta}\end{array}$ & 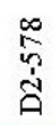 & 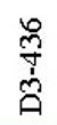 & 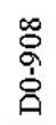 & 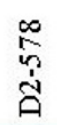 & $\begin{array}{l}\text { ஸे } \\
\text { ஸे }\end{array}$ & $\begin{array}{l}\infty \\
\text { ڤे } \\
\text { ̊े }\end{array}$ & 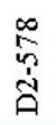 & 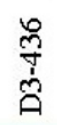 & $\begin{array}{l}\infty \\
\text { ̊े } \\
\text { ஷे }\end{array}$ & 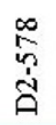 & 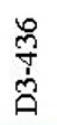 & $\begin{array}{l}\infty \\
\stackrel{人}{0} \\
\dot{े} \\
\text { ̊n }\end{array}$ & 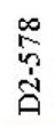 & 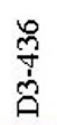 \\
\hline
\end{tabular}

)

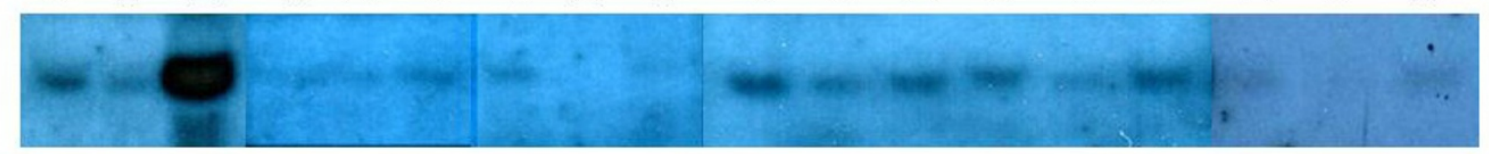

B)

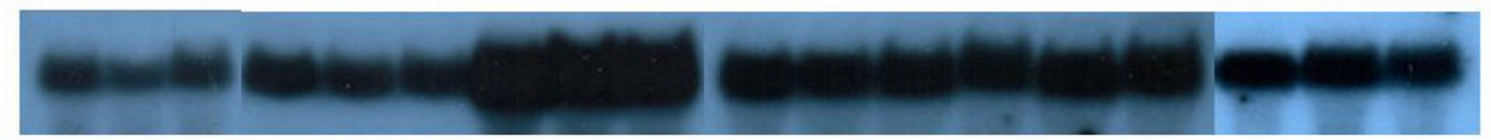

C)

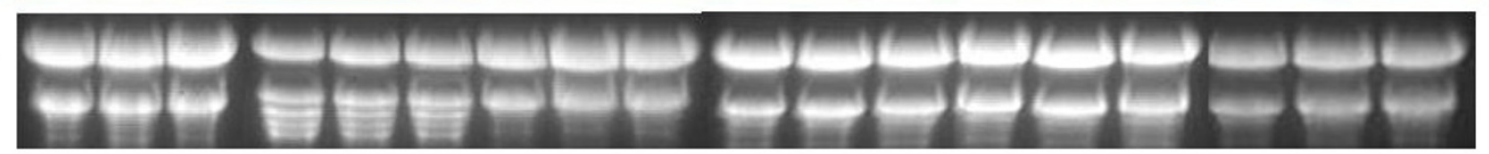

Figure 8 Northern-blot analysis of GUS reporter expression in transgenic tomato plants transformed with full-length ShCYC-B promoter and its deletion fragment constructs. (A) Expression of GUS gene driven by full-length ShCYC-B promoter and its deletion fragments D2-578::GUS and D3-436::GUS, respectively, (B) expression of EF1 $a$ and (C) total RNA loaded per lane in the gel for northern blotting. Total RNA was isolated from the leaf, flower, and fruit tissue at green, breaker, orange and red ripe stage, from single copy transgenic events of each construct. RNA (20-30 $\mu \mathrm{g}$ ) was electrophoresed on a 1.2\% (w/v) formaldehyde agarose gel, transferred onto nylon membranes, and probed with ${ }^{32 P}$-dCTP-labeled GUS gene fragment. The same blot was reprobed with EFla and was used as RNA loading control. The results shown are from tissues of one representative line harboring single copy of transgene for each ShCYC-B promoter construct. 
Table 2: Primers used in this study (Incorporated restriction site sequences are underlined)

\begin{tabular}{|c|c|}
\hline Primer & Sequence (5'-3') \\
\hline Walker1 & $\begin{array}{l}\text { CTA ATA CGA CTC ACT ATA GGG } \\
\text { NNN NA TGC }\end{array}$ \\
\hline Walker2 & $\begin{array}{l}\text { CTA ATA CGA CTC ACT ATA GGG } \\
\text { NNN NT AGC }\end{array}$ \\
\hline Walker3 & $\begin{array}{l}\text { CTA ATA CGA CTC ACT ATA GGG } \\
\text { NNN NG ATC }\end{array}$ \\
\hline Walker4 & $\begin{array}{l}\text { CTA ATA CGA CTC ACT ATA GGG } \\
\text { NNN NC TAG }\end{array}$ \\
\hline Adaptor walker & CTA ATA CGA CTC ACT ATA GGG \\
\hline R1 & GAT AAT GAT CAC GTC GAA TTG AG \\
\hline R2 & CTC TGG CTT TGA TGT GGGT GCT \\
\hline D0-F & $\begin{array}{l}\text { CCC } \underline{\text { AAGCTT GAC TTC ACC CTT CTT }} \\
\text { TCT TGT C }\end{array}$ \\
\hline $\mathrm{D} 1-\mathrm{F}$ & $\begin{array}{l}\text { CCC AAGCTT GAT CTA CTG GAA ATT } \\
\text { GAC CAA C }\end{array}$ \\
\hline D2-F & 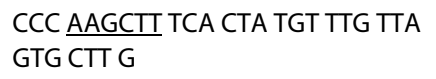 \\
\hline D3-F & $\begin{array}{l}\text { CCC } \underline{\text { AAGCTT GAA CAA TTT TCC TCA }} \\
\text { AAG TTG TAG }\end{array}$ \\
\hline D-R & $\begin{array}{l}\text { CG GGATCC AGA AAA TGT AAA GAT } \\
\text { TGA TAA TGG }\end{array}$ \\
\hline CaMV35S-F & GAA TGC TAA CCC ACA GAT GGTTAG \\
\hline GUS-R & GTT CAA CGC TGA CAT CAC CAT TG \\
\hline$C Y C-B-F$ & GGG TAA TGA GCC ATA TIT AAG GG \\
\hline$C Y C-B-R$ & TAG GAT CCA GAT CAA AGA AAG CG \\
\hline EFla-F & TGG TCATTG GTC ATG TTG A \\
\hline EFla-R & GCA GAT CAT TTG CTT GAC ACCAAG \\
\hline
\end{tabular}

ShCYC-B promoter deletions and promoter-GUS reporter gene constructs

The 908 bp 5' upstream to ATG of the $C Y C-B$ was considered as full-length $S h C Y C-B$ promoter in this study and was designated as D0-908. The 5 ' deletion fragments of D0-908 namely D1-818, D2-578 and D3-436 (D1, D2, and D3 indicates deletions, the numbers after the hypen indicates number of nucleotides upstream to ATG present in the deletion fragment) were amplified with vent ${ }^{\circ}$ DNA polymerase (New England Biolabs, Beverly, MA) using forward primers (D0-F, D1-F, D2-F, D3-F) with Hind III restriction site and one common reverse primer (D-R) with Bam HI site at their 5 ' end (Table 2). The amplified fragments were digested with Hind III and Bam HI restriction enzyme and cloned in to pBI121 by replacing CaMV35S promoter. The pBI121 binary vector was used as positive control (Fig. 3). The binary vectors pBI121, pD0-908 (full-length promoter construct) and pD1-818, pD2-578, pD3-436 (truncated constructs) were trans- formed into Agrobacterium strain LBA4404 by freezethaw method. Plasmid was isolated from transformed Agrobacterium cultures and was back-transformed into E. coli $(\mathrm{DH} 5 \alpha)$ for further confirmation by PCR and restriction analysis of plasmids. The confirmed Agrobacterium harboring pBI121, full-length promoter and its deletion fragments driving GUS reporter gene were used for transient and stable (transgenic) expression analyses in tomato plants.

\section{Transient expression assay}

Transient expression analysis of $S h C Y C-B$ promoter was carried out by fruit agroinjection method as described by Orzaez et al [39]. Agrobacterium culture (5 mL) harboring pBI121 ( $\mathrm{P}_{\text {CaMV355: }}:$ GUS reporter), pD0-908, pD1-818, $\mathrm{pD} 2-578$ and $\mathrm{pD} 3-436$ were grown overnight from individual colonies at $28^{\circ} \mathrm{C}$ in YEM medium ( $\mathrm{pH}$ 6.8) containing kanamycin $\left(50 \mu \mathrm{g} \mathrm{mL}^{-1}\right)$ and rifampicin $\left(25 \mu \mathrm{g} \mathrm{mL}^{-1}\right)$. The culture was then inoculated in to $50 \mathrm{~mL}$ induction medium (YEM medium, $\mathrm{pH}$ 6.8, supplemented with 20 $\mathrm{mM}$ acetosyringone and antibiotics) and grown overnight. Next day, bacterial cells were recovered by centrifugation, resuspended in infiltration medium $(10 \mathrm{mM}$ $\mathrm{MgCl}_{2}, 10 \mathrm{mM}$ MES, $200 \mathrm{mM}$ acetosyringone, $\mathrm{pH}$ 5.6) and incubated at room temperature with gentle agitation (20 rpm) for 2-3 h. Cultures were agroinjected into green and red fruits of tomato (S. lycopersicum var. Pusa Ruby). On third day, non-injected (control) and agroinjected fruits were harvested and transverse sections of the fruit were subjected to GUS histochemical staining as described by Jefferson, [40]. Following the staining, the samples were fixed in $70 \%(\mathrm{v} / \mathrm{v})$ ethanol.

\section{Genetic transformation of tomato}

Transformation of tomato (S. lycopersicum cv. Pusa Ruby) was performed following the method of Cortina and Culianez-Macia [41]. Cotyledons were cut in to 2-3 pieces and pre-cultured for 2 days. The pre-cultured pieces were inoculated with transformed Agrobacterium for $15 \mathrm{~min}$ and co-cultivated for 2 days. The shoots were regenerated under kanamycin selection $\left(50 \mu \mathrm{g} \mathrm{mL}^{-1}\right)$. The regenerated plants were hardened and then transferred to glass house of National Phytotron Facility, IARI, New Delhi. The presence of the $C Y C-B$ promoter::GUS transgene in the transgenic plants was confirmed by PCR using promoter specific forward (D0-F, D1-F, D2-F, D3-F) and GUS-specific reverse primers (Table 2) with genomic DNA extracted from young leaves of $\mathrm{T}_{0}$ plants as templates. Fruits from transgenic plants of each construct were examined for GUS expression by histochemical analysis. The $\mathrm{T}_{1}$ seeds from independent events of each construct were germinated on MS medium supplemented with kanamycin $\left(75 \mu \mathrm{g} \mathrm{mL}^{-1}\right)$ and further screened by PCR analysis using promoter and GUS-specific primers as 
described for $\mathrm{T}_{0}$ plants. At least 2-3 independent transgenic events from each construct were examined for stable integration of transgene and its copy number by Southern hybridization (Additional file 1, Figure S1). Single copy transgenic plants were carried further for GUS histochemical assay, quantitative MUG assay and Northern hybridization.

\section{GUS assay}

The histochemical assay and fluorometric assay for GUS reporter gene expression were done as described by Jefferson [40] with some modifications. For histochemical GUS analysis, roots, leaves, flower and fruits at different stages of ripening $v i z$. early green, mature green, breaker, orange and red ripe, were collected from wild type $(S$. lycopersicum cv. Pusa Ruby) and transgenic plants harboring pBI121(P $P_{\text {CaMV355: }}: G U S$ reporter), pD0-908 (fulllength $C Y C-B:: G U S$ promoter), pD1-818, pD2-578 and pD3-436 (truncated $C Y C-B$ promoter::GUS constructs) transgenes. The flowers and leaves were immersed as whole, while fruits were cut in transverse sections and incubated in GUS staining solution $(0.5 \mathrm{mM} \mathrm{X}$-gluc, 0.1 $\mathrm{M} \mathrm{NaHPO}{ }_{4} \mathrm{pH}$ 8.0, $0.5 \mathrm{mM} \mathrm{K}_{3} \mathrm{Fe}(\mathrm{CN})_{6}, 0.5 \mathrm{mM}$ $\mathrm{K}_{4} \mathrm{Fe}(\mathrm{CN})_{6}, 0.01 \mathrm{M}$ EDTA pH8.0, 20\% methanol and 0.1\% Triton X-100) and incubated overnight at $37^{\circ} \mathrm{C}$. After staining, sections were rinsed in $75 \%$ ethanol for $2-3$ times, and photographed.

Quantitative GUS activity was determined by measuring production of 4-methylumbelliferone (4-MU). For this, samples from 2-3 lines of single copy transgenic lines (two events per construct) were pooled, and used for quantitative MUG assay. Plant tissues were homogenized in $0.4 \mathrm{~mL}$ protein extraction buffer $\left(0.1 \mathrm{M} \mathrm{NaPO}_{4}, \mathrm{pH} 8.0\right.$, $0.1 \%$ SDS, $10 \mathrm{mM}$ EDTA, $10 \mathrm{mM} \beta$-ME, $0.1 \%$ Triton X100) followed by centrifugation at $13,000 \times g 4^{\circ} \mathrm{C}$ for 15 $\mathrm{min}$. The supernatant was used for protein quantification and fluorometric assay. Fifty microliters of supernatant was transferred in to a microcentrifuge tube containing $500 \mu \mathrm{L}$ GUS reaction buffer (protein extraction buffer containing $10 \mathrm{mM}$ MUG) pre-warmed to $37^{\circ} \mathrm{C}$ and mixed. One hundred microliters of this mixture was immediately transferred into a $900 \mu \mathrm{L}$ GUS stop buffer $\left(0.2 \mathrm{M} \mathrm{Na}_{2} \mathrm{CO}_{3}\right)$ to serve as a control. The sample reaction mixture was incubated at $37^{\circ} \mathrm{C}$. One hundred microliters of aliquots were removed at 15, 30, 60 and $120 \mathrm{~min}$ intervals and mixed with $900 \mu \mathrm{L}$ GUS stop buffer. GUS activity was measured in fluorometer (VersaFluor, BioRad, Hercules, CA) with excitation at $365 \mathrm{~nm}$ and emission at $455 \mathrm{~nm}$. The amount of 4-MU was determined from a standard curve. Protein concentrations of the samples were determined using Bradford reagent (BioRad, Hercules, CA) and BSA as a standard. GUS activity was expressed as pmol 4-MU mg protein ${ }^{-1} \mathrm{~min}^{-1}$. Data are presented as the mean ( \pm standard error) of GUS activity from three independent determinations.

\section{RT-PCR and Northern-blot analyses}

Total RNA was isolated from the leaves, flower and fruits at different stages of development from wild type cv. Pusa Ruby (S. lycopersicum) and S. habrochaites genotype EC520061 using RNeasy plant mini kit (QIAGEN). Wild type fruits were sampled at green, breaker, orange and red ripe stage. As genotype EC520061 is green fruited, progress of ripening was broadly defined on the basis of seed color and development. The seed color changed from green to light yellow to dark brown therefore stages were defined as green seeded fruit as immature, light yellow seeded as mature green, dark yellow seeded equivalent to breaker, brownish seeded as equivalent to orange and dark brown seeded as ripe stage. For RT-PCR experiments, first-strand cDNA was synthesized from $250 \mathrm{ng}$ of the DNase-treated RNA in a final volume of $20 \mu \mathrm{L}$ using anchored oligo (dT) of 18-mers according to the manufacturer's instructions (Sensiscript ${ }^{\circ}$ RT kit, QIAGEN). One microlitre of first-strand cDNA was used as template in PCR for analysis using $C Y C-B$ gene specific primers. Elongation factor $1 \alpha(E F 1 \alpha)$ gene primers (Table 2) were used as internal control in $50 \mu \mathrm{L}$ reaction volume. The conditions of the PCR were: $94^{\circ} \mathrm{C}$ for $4 \mathrm{~min}$; 30 cycles of $94^{\circ} \mathrm{C}$ for $50 \mathrm{~s}, 59^{\circ} \mathrm{C}$ for $50 \mathrm{~s}, 72^{\circ} \mathrm{C}$ for $50 \mathrm{~s}$; and final extension at $72^{\circ} \mathrm{C}$ for $5 \mathrm{~min}$. The PCR products were separated on $1.4 \%$ agarose gel. To eliminate the possibility of PCR amplification from genomic DNA contamination in RNA samples, a control RT-PCR reaction was carried out without adding reverse transcriptase.

For Northern hybridization, samples from single copy transgenic events were used for total RNA isolation. Wherever required two independent transgenic events carrying single copy of deletion constructs were used for further confirmation of results. About 20-30 $\mu \mathrm{g}$ of total RNA was fractionated on $1.2 \%(\mathrm{w} / \mathrm{v})$ formaldehyde agarose gel electrophoresis transferred onto Hybond $\mathrm{N}^{+-}$ Nylon membranes (GE Healthcare) by capillary transfer. After transfer, RNA was fixed by UV-cross linking and hybridized with $\left[\alpha-{ }^{32} \mathrm{P}\right] \mathrm{dCTP}$-labeled GUS cDNA fragment corresponding to the entire GUS open reading frame. Blots were rehybridized using a $\left[\alpha-{ }^{32} \mathrm{P}\right] \mathrm{dCTP}-$ labeled $E F l \alpha$ probe as a control for RNA loading.

\section{Additional material}

\footnotetext{
Additional file $1 \mathrm{Fig}$. S1. Representative blots for Southern analysis of $\mathrm{T}_{1}$ transgenic plants harboring $C Y C-B$ full-length promoter and its deletion fragments. GUS coding sequence excised from $\mathrm{pBI} 121$ was used as probe; +ve, GUS CDNA; WT, wild-type; D0-2-1, D0-4-1, and D0-4-3, T, transgenic lines of full-length promoter; D1-2-1, D1-4-1, D1-4-2 and D1-5-2, $\mathrm{T}_{1}$ transgenic plants of D1-818; D2-3-1, D2-3-3, D2-7-1, D2-7-2, D2-8-1 and D2-8-2, $T_{1}$ transgenic plants of D2-578; D3-1-3, D3-2-2, and D3-3-1, $T_{1}$ transgenic plants of D3-436.
} 


\section{Abbreviations}

LYC-B: Chloroplast-specific lycopene $\beta$-cyclase; CYC-B: Chromoplast-specific lycopene $\beta$-cyclase; SNP: Single Nucleotide Polymorphism; CAPS: Cleaved Amplified Polymorphic Sequence; MUG: 4-methylumbelliferone glucuronide; GUS: $\beta$ glucuronidase; TSS: Transcription Start Site

\section{Authors' contributions}

MD: performed all the experiments. VC assisted with DNA sequence analysis and histochemical GUS analysis. KCB together with MD and VC designed the experiments and wrote the manuscript. All authors read and approved the manuscript.

\section{Acknowledgements}

This study was supported by the financial grant from Department of Biotechnology (DBT), Govt. of India, New Delhi to KCB. The authors are thankful to Dr. KV Prabhu, National Phytotron Facility, IARI, New Delhi, for providing Phytotron facility, and Dr. (Mrs.) G. J. Randhawa, NBPGR, New Delhi for facilitating the fluorometric analysis of reporter gene.

\section{Author Details}

'National Research Centre on Plant Biotechnology, Indian Agricultural Research Institute, New Delhi - 110012, India, 2Directorate of Sorghum Research, Hyderabad -500 030, India and ${ }^{3}$ Water Technology Centre, Indian Agricultural Research Institute, New Delhi - 110012, India

Received: 25 November 2009 Accepted: 9 April 2010 Published: 9 April 2010

\section{References}

1. Bramley PM: Regulation of carotenoid formation during tomato fruit ripening and development. Journal of Experimental Botany 2002, 53:2107-2113

2. Hirschberg J: Carotenoid biosynthesis in flowering plants. Current Opinion in Plant Biology 2001, 4:210-218.

3. Zar BA, Zacaryas L, Rodrigo MJ: Molecular and functional characterization of a novel chromoplast-specific lycopene $\beta$-cyclase from Citrus and its relation to lycopene accumulation. Journal of Experimental Botany 2009, 60(6):1783-1797.

4. Charles A-D, McGhie T, Wibisono R, Montefiori M, Hellens RP, Allan AC: The kiwifruit lycopene beta-cyclase plays a significant role in carotenoid accumulation in fruit. Journal of Experimental Botany 2009, 60(13):3765-3779.

5. Ha SH, Kim JB, Park JS, Lee SW, Cho KJ: A comparison of the carotenoid accumulation in Capsicum varieties that show different ripening colours: deletion of the capsanthin-capsorubin synthase gene is not a prerequisite for the formation of a yellow pepper. Journal of Experimental Botany 2007, 58:3135-3144.

6. Giuliano G, Bartley GE, Scolnik P: Regulation of carotenoid biosynthesis during tomato development. Plant Cell 1993, 5:379-387.

7. Fraser PD, Truesdale MR, Bird CR, Schuch W, Bramley PM: Carotenoid biosynthesis during tomato fruit development. Plant Physiology 1994, 105:405-413.

8. Corona V, Aracci B, Kosturkova G, Bartley GE, Pitto L, Giorgetti L, Scolnik PA, Giuliano G: Regulation of a carotenoid biosynthesis gene promoter during plant development. Plant Journal 1996, 9:505-512.

9. Alba R, Payton P, Fei Z, McQuinn R, Debbie P, Martin GB, Tanksley SD, Giovannoni JJ: Transcriptome and selected metabolite analyses reveal multiple points of ethylene control during tomato fruit development. Plant Cell 2005, 17:2954-2965.

10. Pecker I, Gabbay R, Cunningham FX, Hirschberg J: Cloning and characterization of the CDNA for lycopene $\beta$-cyclase from tomato reveals decrease in its expression during fruit ripening. Plant Molecular Biology 1996, 30:807-819.

11. Ronen G, Cohen M, Zamir D, Hirschberg J: Regulation of carotenoid biosynthesis during tomato fruit development: expression of the gene for lycopene epsilon-cyclase is down-regulated during ripening and is elevated in the mutant Delta. Plant Journal 1999, 17:341-351.

12. Ronen $G$, Carmel-Goren L, Zamir D, Hirschberg J: An alternative pathway to $\beta$-carotene formation in plant chromoplasts discovered by mapbased cloning of Beta and old-gold color mutations in tomato. Proceedings of National Academy of Sciences USA 2000, 97:11102-11107.
13. Aluru M, Xu Y, Guo R, Wang Z, Li S, White W, Wang K, Rodermel S: Generation of transgenic maize with enhanced provitamin A content. Journal of Experimental Botany 2008, 59(13):3551-3562.

14. Ducreux LJM, Morris WL, Hedley PE, Shepherd T, Davies HV, Millam S, Taylor MA: Metabolic engineering of high carotenoid potato tubers containing enhanced levels of beta-carotene and lutein. Journal of Experimental Botany 2005, 56:81-89.

15. Paine JA, Shipton CA, Chaggar S, Howells RM, Kennedy MJ, Vernon G, Wright SY, Hinchliffe E, Adams JL, Silverstone AL, Drake R: Improving the nutritional value of golden rice through increased pro-vitamin A content. Nature Biotechnology 2005, 23:482-487.

16. Ye X, Al-Babili S, Kloti A, Zhang J, Lucca P, Beyer P, Potrykus I: Engineering the provitamin A (beta-carotene) biosynthetic pathway into (carotenoid-free) rice endosperm. Science 2000, 287:303-305.

17. Shewmaker CK, Sheehy JA, Daley M, Colburn S, Ke DY: Seed-specific over expression of phytoene synthase: increase in carotenoids and other metabolic effects. Plant Journal 1999, 20:401-412.

18. Davuluri GR, van Tuinen A, Fraser PD, Manfredonia A, Newman R, Burgess D, Brummell DA, King SR, Palys J, Uhlig J, Bramley PM, Pennings HM, Bowler C: Fruit specific RNAi-mediated suppression of DET1 enhances carotenoid and flavanoid content in tomatoes. Nature Biotechnology 2005, 23:890-895.

19. Dharmapuri S, Rosati C, Pallara P, Aquilani R, Bouvier F, Camara B, Giuliano G: Metabolic engineering of xanthophyll content in tomato fruits. FEBS Letters 2002, 519:30-34

20. Romer S, Fraser PD, Kiano JW, Shipton CA, Misawa N, Schuch W, Bramley PM: Elevation of the provitamin A content of transgenic tomato plants. Nature Biotechnology 2000, 18:666-669.

21. Rosati C, Aquilani R, Dharmapuri S, Pallara P, Marusic C, Tavazza R, Bouvier F, Camara B, Giuliano G: Metabolic engineering of beta-carotene and lycopene content in tomato fruit. Plant Journal 2000, 24:413-419.

22. Davuluri GR, Van Tuinen A, Mustilli AC, Manfredonia A, Newman R, Burgess D, Brummell DA, King SR, Palys J, Uhlig J, Pennings HM, Bowler C: Manipulation of $D E T 1$ expression in tomato results in photomorphogenic phenotypes caused by post-transcriptional gene silencing. Plant Journal 2004, 40:344-354.

23. Pecker I, Chamovitz D, Linden H, Sandmann G, Hirschberg J: A single polypeptide catalyzing the conversion of phytoene to $\beta$-carotene is transcriptionally regulated during tomato fruit ripening. Proceedings of National Academy of Sciences USA 1992, 89:4962-4966.

24. Galpaz N, Ronen G, Khalfa Z, Zamir D, Hirschberga J: A chromoplastspecific carotenoid biosynthesis pathway is revealed by cloning of the tomato white-flower locus. Plant Cell 2006, 18:1947-1960.

25. Seo M, Koshiba T: Complex regulation of ABA biosynthesis in plants. Trends in Plant Science 2002, 7:41-48.

26. Giuliano G, Tavazza R, Diretto G, Beyer P, Taylor MA: Metabolic engineering of carotenoid biosynthesis in plants. Trends in Biotechnology 2008, 26:139-145.

27. Fray RG, Wallace A, Fraser PD, Valero D, Hedden P, Bramley PM, Grierson D: Constitutive expression of a fruit phytoene synthase gene in transgenic tomatoes causes dwarfism by redirecting metabolites from the gibberellins pathway. Plant Journal 1995, 8:693-701.

28. Galpaz N, Wang Q, Menda N, Zamir D, Hirschberg J: Abscisic acid deficiency in the tomato mutant high-pigment 3 leading to increased plastid number and higher fruit lycopene content. Plant Journal 2008, 53:717-730

29. Bang H, Kim S, Leskovar D, King S: Development of a codominant CAPS marker for allelic selection between canary yellow and red watermelon based on SNP in lycopene $\beta$-cyclase (LCYB) gene. Molecular Breeding 2000, 20:63-72.

30. Reese MG: Application of a time - delay neutral network to promote annotation in the Drosophila melanogaster genome. Computer chemistry 2001, 26(1):51-56.

31. Higo K, Ugawa Y, Iwamoto M, Korenaga T: Plant cis-acting regulatory DNA elements (PLACE) database: 1999. Nucleic Acids Research 1999, 27:297-300

32. Lescot M, Déhais P, Moreau Y De Moor B, Rouzé P, Rombauts S: PlantCARE: a database of plant cis-acting regulatory elements and a portal to tools for in silico analysis of promoter sequences. Nucleic Acids Res Database issue 2002, 30(1):325-327.

33. Welsch R, Maass D, Voegel T, DellaPenna D, Beyer P: Transcription facto RAP2.2 and its interacting partner SINAT2: stable elements in the 
carotenogenesis of Arabidopsis leaves. Plant Physiology 2007, 145:1073-1085.

34. Welsch R, Medina J, Giuliano G, Beyer P, von Lintig J: Structural and functional characterization of the phytoene synthase promoter from Arabidopsis thaliana. Planta 2003, 216:523-534.

35. Villain $P$, Mache R, Zhou D-X: The mechanism of GT element-mediated cell type-specific transcriptional control. Journal of Biological Chemistry 1996, 271:32593-32598.

36. Gourrierec JL, Li Y-F, Zhou D-X: Transcriptional activation by Arabidopsis GT-1 may be through interaction with TFIIA-TBP-TATA complex. Plant Journal 1999, 18:663-668.

37. Misra RN, Singla-Pareek SL, Nair S, Sopory SK, Reddy MK: Directional genome walking using PCR. BioTechniques 2002, 33:830-834.

38. Doyle JJ, Doyle JL: Isolation of plant DNA from fresh tissue. Focus 1990, 12:13-15

39. Orzaez D, Mirabel S, Wieland WH, Granell A: Agroinjection of tomato fruits. A tool for rapid functional analysis of transgenes directly in fruit. Plant Physiology 2006, 140:3-11.

40. Jefferson RA, Kavanagh TA, Bevan MW: GUS fusions: $\beta$-glucuronidase as a sensitive and versatile gene fusion marker in higher plants. $E M B O$ Journal 1987, 6:3901-3907

41. Cortina C, Culianez-Macia FA: Tomato transformation and transgenic plant production. Plant Cell, Tissue and Organ Culture 2004, 76:269-275.

doi: $10.1186 / 1471-2229-10-61$

Cite this article as: Dalal et al., Isolation and functional characterization of Lycopene ?-cyclase (CYC-B) promoter from Solanum habrochaites BMC Plant Biology 2010, 10:61

Submit your next manuscript to BioMed Central and take full advantage of:

- Convenient online submission

- Thorough peer review

- No space constraints or color figure charges

- Immediate publication on acceptance

- Inclusion in PubMed, CAS, Scopus and Google Scholar

- Research which is freely available for redistribution

Submit your manuscript at www.biomedcentral.com/submit
C) Biomed Central 